\title{
Civilización o Barbarie
}

Aportes al debate en torno a la misión civilizadora del Trabajo Social y las posibilidades de construcción de poder popular

El Trabajo Social como hecho político de la hegemonía colonizadora

Andrea Marina Sumalla Licenciada en Trabajo Social (UNR) Correo: andreasumalla@gmail.com 
Resumen

Retomando un fragmento de mi tesina de grado presentada en el año 2012 en la Escuela de Trabajo Social de la UNR, bajo la dirección del Mg. José María Alberdi, el presente artículo se plantea el objetivo de reflexionar en torno a la posibilidad del Trabajo Social de ser instrumento en manos de la hegemonía civilizadora. Históricamente el proyecto profesional hegemónico dentro del colectivo de profesionales estuvo ligado al sostenimiento de la lógica capital-trabajo. Aunque también resulta necesario realizar una problematización sobre la razón del surgimiento del Trabajo Social profesionalizado lejos del velo de la historia oficial. El espacio ocupacional del Trabajo Social se encuentra en el centro de la tensión civilización-barbarie, es por ello que nos planteamos tales ejes a fin de repensar nuestras prácticas cotidianas. Las intervenciones pueden sostener el statu quo, así como también tienen el poder de ser utilizadas para la transformación social. Con fines analíticos hemos dividido el escrito en tres corrientes de Trabajo Social: una de tipo conservadora, otra ligada al pensamiento marxista y una tercera sostenida sobre la tradición nacional y popular.

\section{Palabras claves}

Civilización - Barbarie - Trabajo Social - Poder Popular
Abstract

Taking up a fragment of my degree thesis presented in 2012 at the National University of Rosario, School of Social Work, under the direction of Mg. José María Alberdi (current director of that school), this article in order to reflect on the possibility of social work of being an instrument in the hands of the civilizing hegemony arises. Historically the hegemonic professional project within the group of professionals in social work was linked to the support of logic working capital. Although it is also necessary to make a problematization on the reason for the emergence of social work professionalized away the veil of official history. Occupational social work space is located in the center of civilization tension - barbarism, which is why we set such axes to rethink our daily practices. Interventions can sustain the status quo, and also have the power to be used for social transformation. Making a brief tour of the currents of thought on which the exercise of social work professionals currently supported. For analytical purposes we have divided into three streams written social work: one of conservative type, another social work linked to Marxist thought and a form of social work held on the national and popular tradition. In order to think and reflect about the possibility of it to build popular power.

Keywords

Civilization - Barbarism - Social

Work - Popular Power 


\section{Introducción}

Los ejes de civilización y barbarie atraviesan a las diferentes visiones y ejercicios del Trabajo Social, tanto como éste atraviesa a tales ejes. La construcción de una sociedad desigual implica a ambos componentes, la argumentación conceptual que funda a nivel simbólico, tanto como los instrumentos utilizados para materializar el poder hegemónico.

Desde sus inicios, el proyecto profesional hegemónico del Trabajo Social se encontraba ligado al sostenimiento de la lógica capitaltrabajo. Las instituciones en las cuales se insertan los profesionales del Trabajo Social tuvieron su surgimiento en condiciones históricosociales particulares. En Argentina, las instituciones que abordaron la cuestión social con financiamiento público, surgieron a partir de la oleada inmigratoria que data de entre mediados del siglo XIX y las primeras décadas del XX. Este hormiguero inmigratorio es el que fundó las primeras organizaciones de la clase obrera en la lucha por la salida de su situación miserable ${ }^{1}$. Por lo tanto, ésto evidencia que el surgimiento de las instituciones estatales que brindan asistencia a las necesidades de las clases populares, con financiamiento público, resultan una respuesta de las luchas de la clase trabajadora. Estas instituciones estatales y los trabajadores sociales que se insertan en ellas son parte de la conquista del financiamiento público por parte de la clase trabajadora: "La clave está en entender que no es por el pedido de limosna ni por las acciones de caridad que surge el Trabajo Social, sino que se relaciona con los reclamos de las organizaciones de trabajadores, es decir, no fueron demandas individuales sino demandas colectivas" (Oliva, 2008:56).

Aunque la historia oficial del Trabajo Social no establezca de forma explícita su surgimiento como profesión a partir de la demanda colectiva, en sus inicios la formación profesional del Trabajo Social

1 "La reproducción de la fuerza de trabajo como el elemento que, al motorizar la valorización del capital, se encuentra en una relación de contradicción con el mismo, manifestando en ese intercambio desigual la génesis de innumerables problemáticas que trascienden la esfera laboral y conforman algunos de los matices de la cuestión social, campo indiscutible de desarrollo del Trabajo Social en sus variadas expresiones" Bentos (2008). 
en Argentina, a partir de la década del 30, contaba en su plan de estudio con la asignatura Servicio Social Colectivo, reconociendo la necesidad nacional de abordar las problemáticas ligadas a la cuestión obrera-inmigrante. El Servicio Social de Caso Individual, tan nombrado como el pionero Servicio Social, fue una respuesta liberal a las luchas de la clase obrera, un intento de fragmentar el colectivo mediante respuestas moralizantes ${ }^{2}$ y normalizantes ${ }^{3}$, con un claro espíritu civilizador de las clases dominantes presente en el proyecto profesional hegemónico del Trabajo Social desde sus inicios.

El espacio ocupacional del Trabajo Social se enmarca en la presente lucha de clases siendo un eje en tensión, ya que el mismo movimiento que permite la reproducción de la sociedad de clases, crea las posibilidades de transformación de la misma. Esto porque el ejercicio del Trabajo Social se realiza desde la participación en el proceso de reproducción de los intereses de preservación del capital y de las necesidades de sobrevivencia de los trabajadores (Oliva, 2006:74-75): "Es parte de lo que Álvarez-Uría llama la ambigüedad constitutiva y constituyente del Trabajo Social, puesto que tiene que "promover el cambio, pero sin alterar el orden». Esta ambivalencia confronta ineludiblemente al profesional con su rol de delegado de dichas estructuras y le hace partícipe del poder que detentan” (Pellegrí Viaña, 2004:22).

2 La moralización tiene su punto neurálgico en la enseñanza por parte del profesional a sus objetos de intervención, como forma de "bajar" los conocimientos y pensamientos necesarios para la vida en sociedad. Donzelot dice al respecto: "es necesario que esas ayudas sirvan para algo, que provoquen un enderezamiento de la familia. Por eso en toda petición de ayuda hay que vigilar y sacar a la luz la falta de moral que más o menos directamente la determina: esa parte de negligencia y de pereza, de relajación que hay en toda miseria. Conexión sistemática de la moral con lo económico, que implicará una vigilancia continua de la familia una penetración integral en el más mínimo detalle de su vida" (1998:71)

3 "El poder disciplinario encarna las acciones que Foucault denomina 'prácticas que dividen', cuyo objeto principal es construir sistemas de clasificación y, mediante ellos, diferenciar lo normal de lo que no lo es. La 'normalización' de la población implica el desarrollo de formas de saber que establecen ideales de pensamiento y conducta humanos, frente a los cuales los individuos son evaluados para actuar discretamente sobre ellos y conformarlos a la norma; se trata de una tecnología de poder que se desarrolla a partir de la 'verdad' que instituye el saber de las disciplinas. Dice Foucault: 'por verdad [hay que] entender un conjunto de procedimientos reglamentados por la producción, la ley, la repartición, la puesta en circulación, y el funcionamiento de los enunciados' (Foucault, 1992a:189). Lo importante es, pues, entender que se producen efectos de verdad en el interior de los discursos (tanto teóricos como prácticos) que no son en sí mismos ni verdaderos ni falsos, pero que crean 'regímenes políticos, económicos, etc. de producción de verdad'” (Pellegrí Viaña, 2004:31). 
El quehacer del Trabajo Social desde sus diferentes posicionamientos y en las distintas instituciones en las que se inserta, interviene en la esfera de la producción y reproducción de la vida social, y en este acto se constituye como profesión surgida del interés político de las clases hegemónicas, con la intención de establecer dispositivos de control para limitar las posibilidades de poder de la clase obrera, a fin de perpetuar el statu quo (Bentos, 2008:4-5). El Trabajo Social, en términos concretos, interviene en la mediación entre la producción material y la reproducción del sujeto para esta producción, y en la mediación de la representación del sujeto en esta relación (Faleiros, 2007:107), interviniendo en la clase trabajadora en tanto ocupada, transitoriamente desocupada o precarizada en sus relaciones laborales. Es en esta dimensión en la que es posible reorientar el sentido de la práctica profesional ya que "abre la posibilidad de neutralizar la alienación de la actividad para el sujeto que la realiza, a pesar de no eliminar la existencia de procesos de alienación que envuelven el trabajo asalariado" (Iamamoto, 2003:121).

\section{Civilización, barbarie y Trabajo Social}

En el colectivo profesional de Trabajo Social contemporáneo podemos encontrar diferentes posicionamientos ideológico-académicopolíticos que marcan una postura frente a los ejes trabajados. Los mismos son los siguientes: conservador (dentro de éste un posicionamiento filantrópico a nivel civil, ya sea laico o vinculado a la caridad cristiana, y un posicionamiento liberal en el marco de la actividad estatal), marxista y nacional-popular (Gallo, 2007:10-12).

\section{Trabajo Social Conservador}

Dentro de lo clasificado como Trabajo Social conservador encontramos "concepciones del mundo y de la vida (que tratan) de naturalizar las situaciones de injusticia, discriminación y desigualdad; (...) 
trabaja en escala micro para los intereses de los grupos privilegiados de la economía; es decir (...) Su noción principal es que el pobre representa la peligrosidad y la ignorancia. Su lógica política de intervención será, entonces, aislar a unos y reeducar a otros. El encierro y la introyección de pautas y normas de vida conservadoras serían las soluciones. Para el Trabajo Social conservador el reparto de recursos es un antídoto contra los conflictos sociales. La misión es entonces procurar un estricto control y vigilancia social en los sectores empobrecidos (...) Ante las organizaciones populares la política del trabajador social conservador es romperlas mediante estrategias de control y cooptación" (Gallo, 2007:10-11).

Dentro de la historia del Trabajo Social argentino, podemos encontrar este posicionamiento en la propuesta de Trabajo Social de Delia Franco explicitada en su libro de formación académica para las escuelas de Trabajo Social, durante la década del 40 y 50. Dicha autora en el año 1947 decía: "Doctrina sociológica deducida a su vez de un principio inmutable y superior capaz de establecer la obligatoriedad de la asistencia social, no por la fuerza de la ley humana sino en virtud de un mandato divino (...) La esencia misma de la asistencia social estará dada por el cristianismo y su base son la caridad y la justicia cristianas" (Franco, 1947:12). Aquí el abordaje de lo social está teñido de una visión religiosa y filantrópica que coloca al Trabajo Social como instrumento para objetivos que sobrepasan los objetivos mismos de la asistencia concreta. De esta forma, el accionar del Trabajo Social se basaría en los preceptos producidos en la doctrina cristiana-católica. En la asistencia caritativa lo importante, o el eje de tal transacción, no es el sujeto que recibe lo donado sino aquel que realiza tal acto de asistencia.

Históricamente, en Argentina la asistencia es laicalizada a partir de la creación de la Sociedad de Beneficencia ${ }^{4}$ en 1823. Aunque fue

4 “(...) esta institución suege como parte del proyecto rivadavino de incorporación del país al capitalismo mundial, basado en los principios de 'orden y progresóy apuntando a un desarrollo comercial, el cual resulta frustrado y sólo en las últimas décadas del siglo XIX se efectivizó. Dentro de este contexto, el carácter secularizado de la Sociedad, construido con un sentido filantrópico y limitando el papel de la Iglesia, implicó un avance considerable a la mera atención caritativa cristiana. El contenido moralizante de las actividades de la Sociedad se fundan en una moral moderna y racional. Si bien, dado el carácter incipiente del desarrollo capitalista, el peso dominante de la elite terrateniente 
un gran cambio, la intervención se continuaba realizando no sobre las necesidades de los sectores populares, sino en las mismas clases populares, en sus vidas cotidianas desde un punto de vista moralizador. La asistencia filantrópica estaba a cargo de las elites dominantes.

Por último, el posicionamiento del Trabajo Social de tipo conservador también adopta una forma liberal dentro del espectro estatal. Esta lógica de Trabajo Social encuentra sus inicios en Argentina en el posicionamiento esgrimido por la Escuela de Asistencia Social de la década del '30. En el año 1933 se realiza la Primera Conferencia Nacional de Asistencia Social en la que Alberto Zwanck, fue presidente y Germinal Rodríguez, uno de los vocales. "En dicha Conferencia se concluía en que 'existe un consenso generalizado en considerar a la Asistencia Social como orientada a lograr el ajuste del individuo a la sociedad'. A su vez, se expresaba que el 'mejoramiento social del individuo y de la familia', se alcanzará mediante una acción de difusión e inculcación de 'todos aquellos medios y conocimientos que aconsejan la higiene física y mental"” (Gallo, 2006:170).

Este tipo de posicionamiento hoy lo podemos encontrar en aquellos profesionales que, acordando conscientemente o no con las posturas neoliberales de los años pasados más recientes, llevan adelante una práctica de Trabajo Social conservador-liberal, poco crítico y en favor de las minorías hegemónicas. Desde la reapertura democrática, en nuestra profesión una línea del Trabajo Social retorna a las instituciones para "ayudar y asistir al necesitado", desde un trabajo individualizante y fragmentado abocando más al espacio intrafamiliar que al escenario comunitario (Dell’Aglio, 2011:15-16). La realización de tal estrategia antipopular puede darse también por lo que Netto llama "cinismo profesional", esto es, "ejercitar sus atribuciones institucionales, o sea, desempeñar aquellos papeles, roles, o sea sólo ejecutar las atribuciones que le están asignadas por la institución" (Netto, 1997). Su posición es la de "yo hago lo que es posible" frente a la contradicción diaria de tener que sostener su espacio laboral,

y la fuerte presencia de elementos tradicionalistas, encontramos una vinculación indirecta con la Iglesia; en gran parte esta moral se define por su relación con las virtudes cristianas" (Parra, 2001: 110-111) 
vital para cualquier asalariado, a cambio de no realizar las transformaciones que querría llevar adelante en el mismo.

Este perfil profesional liberal también "fue acompañado desde la academia por un proceso de transformación donde se hizo hincapié en la elevación del nivel académico para lo cual se sustituyó el trabajo de base para pasar a la formación de técnicos "capacitados" para elaborar y formular buenos diagnósticos y proyectos fragmentando así los aprendizajes, instrumentaron técnicos al servicio de las políticas sociales neoliberales" (Dell'Aglio, 2011:16). Este Trabajo Social liberal-conservador afirmaba al trabajador social como un tecnócrata al servicio del statu quo.

Podemos decir que en el colectivo profesional en Argentina el Trabajo Social conservador no es la postura hegemónica, pero dicho posicionamiento se encuentra presente en algunos profesionales de forma consciente y con una intencionalidad sólidamente argumentada y en otros casos como emergentes esporádicos, no consciente, que sorprenden el cotidiano quehacer profesional, en el cual la vorágine diaria atenta contra la reflexión de la intervención. Los ejes civilización y barbarie son claramente afirmados.

\section{Trabajo Social Marxista}

Desde este posicionamiento se considera al Trabajo Social como un tipo de trabajo en la sociedad, una profesión particular inscripta en la división social y técnica del trabajo colectivo de la sociedad, es decir que el trabajador social es parte de la clase trabajadora. Suponer esto implica aprehender a la práctica profesional condicionada por las relaciones entre el Estado y la Sociedad Civil, por las relaciones entre las clases en la sociedad. La constitución e institucionalización del Trabajo Social depende de la acción del Estado en la regulación de la vida social, cuando pasa a administrar el conflicto de clase. Cuando el Estado comienza a abordar la cuestión social no sólo a través de la coerción sino también a través del consenso, son creadas las bases históricas de nuestra demanda profesional. El Trabajo Social partici- 
pa en la producción-reproducción de la vida social, concentrándose en la vida material. En la tensión entre producción de la desigualdad y producción de la rebeldía y de la resistencia, trabajan los trabajadores sociales situados en ese terreno movidos por intereses sociales distintos, de los cuales no es posible huir, porque constituyen la vida social (Iamamoto, 2003). Faleiros agrega a la intervención en la producción y reproducción de la vida social, la intervención del Trabajo Social en la representación, la cual envuelve manifestaciones de la cultura, de la ideología, del yo, de la vida diaria y de las relaciones de clase de manera heterogénea y confusa. Intervenir en la representación implica el rescate de la identidad en un proceso socio-afectivo (Faleiros, 2007). Desde una perspectiva dialéctica, el Trabajo Social marxista afirma su intervención sobre categorías como la de realidad como totalidad en movimiento, donde las partes se remiten recíprocamente en relaciones de determinación y condicionamiento. Considera que la realidad se expresa en hechos encadenados en procesos históricos y fenómenos que tienen aspectos manifiestos y una esencia a develar. Estos hechos tienen una historicidad que los interrelaciona, y se expresa en un espacio (lugar) determinado. Los hechos y fenómenos de la realidad están relacionados en relaciones de asociación y contradicción. Aquí los procesos sociales son históricos, particulares y concretos, plausibles de ser entendidos en una relación texto-contexto. Parte de la concepción de sujeto colectivo, homogeneizándolo en su condición de clase (Jong, 1998).

En cuanto al par civilización y barbarie, la mayoría de las diferentes corrientes que conforman la izquierda argentina tiene una ambigüedad argumental que culmina en el sostenimiento de la división entre ambos. En términos teóricos, la lectura marxista no deja de considerar la existencia de un movimiento de progreso social, por el cual el último agente de este progreso es la clase obrera, es decir que es la "civilización". La condición necesaria para la superación de la lucha de clases y, por ende, de la consecución de una sociedad armónica e igualitaria, es que la burguesía llegue a su punto máximo de poder en el cual sus propias contradicciones conspirarán para llegar a su caída. La barbarie aquí sería la burguesía y el proletariado el ele- 
mento progresivo. Una lectura mecánica y con tintes evolucionistas llevó a parte de la izquierda a apoyar el colonialismo como única forma de mundializar las relaciones de producción capitalistas y forjar la clase trabajadora que posteriormente realizaría la revolución. En Argentina la izquierda no fue parte de los procesos populares que se dieron a través de la historia nacional. Los movimientos populares federales no fueron apoyados por ser preindustriales y atentar contra la posibilidad de mundialización de la clase obrera revolucionaria. Los demás movimientos populares de la historia argentina (el yrigoyenismo y el peronismo) no fueron apoyados por la izquierda por ser movimientos reformistas.

La historia nacional nos muestra que en frente a los procesos populares de nuestro país, las diferentes facciones de la izquierda nacional no estuvieron en consonancia con el posicionamiento de la mayoría de la clase trabajadora nacional, ya que la misma es reformista per se, la clase obrera históricamente siempre terminó generando una conciencia trade-unionista, es decir una conciencia sindical (Feinmann, 2008). La clase obrera populista y reformista no es nombrada como tal por la izquierda, sino que es nombrada como una clase que es integrada por lúmpenes, es decir por "agitadores sin conciencia”, de esta forma culminan afirmando que la clase trabajadora populista es la "barbarie". Frente a esta situación, desde el Trabajo Social también se sostiene una teoría de la vanguardia iluminada, mediante la cual - considerando a la clase trabajadora como ignorante de su propia conveniencia- se propone su conducción por fuera de la misma y sin la participación activa de los sujetos de la intervención. Caen en el par civilización-barbarie, considerando que los profesionales desde su conocimiento teórico y su conciencia de clase, deben "concientizar", es decir "iluminar" a los sectores populares para su liberación. A su vez, los diferentes posicionamientos de izquierda en el colectivo de Trabajo Social abordan la realidad nacional desde la lectura de teóricos de otras nacionalidades que, aunque fueran latinoamericanos, no contemplan las particularidades nacionales que viven diariamente los sectores populares de nuestro país. Desde "nuestra formación (se) reproduce en forma predominante el viejo estigma de civilización o 
barbarie. Desde las (...) corrientes marxistas ortodoxas toda expresión popular es obra de la enajenación del pueblo. Su religiosidad, su adhesión a líderes populares, su noción del trabajo como dignidad, su participación en los movimientos de masas, sus costumbres y tradiciones merecen el desprecio y la desaprobación de la cátedra y de los intelectuales de moda. Según esta visión elitista, la verdad está en otra parte: reposa en sus teorías y doctrinas que se obstinan en negar la cultura y la historia de los pueblos latinoamericanos. No es casual que los pensadores ligados a los movimientos populares queden excluidos del debate universitario. José Martí, José Carlos Mariátegui, Haya de la Torre, Manuel Ugarte, Arturo Jauretche, Juan José Hernández Arregui, Simón Rodríguez, Jorge Abelardo Ramos, Rodolfo Puiggrós, Raúl Scalabrini Ortiz son ignorados en nuestros círculos de formación. Es lógica, entonces, la dificultad de pensar al Trabajo Social cuando las herramientas teóricas que utilizamos encubren y deforman los reales procesos socio-históricos de los que emerge nuestra profesión” (Gallo, 2005:21).

\section{Trabajo Social enmarcado en la tradición Nacional y Popular}

El planteo de un Trabajo Social nacional y popular ${ }^{5}$ tiene su raíz en la necesidad de contemplar desde las lecturas de la profesión, las

\footnotetext{
5 Este tipo de ejercicio de la profesión se enmarca en el pensamiento nacional y popular, el cual implica los siguientes basamentos: "En el nacionalismo popular el Estado es pensado como un espacio de poder por excelencia donde confrontan las distintas corrientes políticas, y allí se expresan las relaciones de fuerzas de la sociedad civil. Y es el lugar donde se concentran los resortes más potentes de coerción y consenso. En esta corriente, el Estado debe intervenir en la economía procurando, según las relaciones de fuerza existentes, una progresiva distribución de la riqueza a favor del pueblo. En lo económico, aspira a un mercado interno en expansión. Esto significa incentivar la creación de industrias nacionales para que las materias primas generadas en el país sean elaboradas aquí, lo que genera empleo. El Estado protege a esas industrias nacionales mediante el cobro de impuestos elevados a los productos provenientes del exterior, obstaculizando así que esos productos entren al país y reemplacen a los nacionales; con los bancos estatales mediante el crédito a bajas tasas de interés para la promoción y expansión de sus actividades; y por medio de obras de infraestructura. Estas políticas económicas generan un círculo virtuoso ya que con la creación de industrias se genera empleos con lo que disminuye la desocupación y se apunta a la ocupación plena. En base a la política impulsada por el Estado de distribución del ingreso a favor de los trabajadores el salario asciende y ese dinero el trabajador lo vuelca hacia los comercios, con lo que la clase media proletaria de los mismos aumenta las ganancias y emplea a otros trabajadores. A su vez, los sindicatos comienzan a tener mayor relevancia
} 
particularidades de la historia nacional. Cada intervención social requiere de la historización de la situación a intervenir, una lectura de la coyuntura nacional y latinoamericana que determina el camino por el que transita la situación que constituye la materia prima de la intervención, los programas, leyes y otras formas de respuestas estatales a la cuestión social nacional, las formas de organización y construcción de poder popular del pueblo argentino, etc. También es indispensable ubicar esta lectura coyuntural en una visión más amplia que interpele los procesos sociales latinoamericanos, los cuales son fuertemente marcados por los efectos de la conquista europea y del colonialismo económico-financiero que implica para nuestros países latinoamericanos, el imperialismo imperante.

El aspecto popular de este posicionamiento se encuentra ligado a la concepción de los sujetos-ciudadanos de intervención. Los mismos son contados dentro de los sectores populares de Argentina. Al llamar sectores populares a la porción poblacional con la que interviene gran parte del Trabajo Social, y que conforman la población objetivo de numerosas instituciones que componen el espacio ocupacional de la profesión, se hace referencia a los sectores más postergados de nuestra sociedad, los cuales desde los años 70, con la llegada del neoliberalismo, han elaborado nuevas formas de acción colectiva en respuesta a las transformaciones que desestructuraron su mundo de pertenencia. A estos sectores no debemos considerarlos pasivos ya que se han manifestado políticamente de diferentes maneras, por medio de los partidos laboristas y sindicatos, o siendo desocupados buscan nuevas formas de movilización como los cortes de ruta, revueltas y saqueos a comercios y otras formas de estallidos sociales. Nombrarlos de esta manera conlleva considerarlos actores políticos,

y poder, y eso permite que el trabajador deje de estar aislado y tenga un espacio de solidaridad y de lucha. El estado debe impulsar y fortalecer a las organizaciones del pueblo para que estas sean parte del gobierno. El pilar del proyecto de sociedad nacional y popular es la organización del pueblo. El Estado y las organizaciones populares deben controlar los recursos estratégicos de una nación como son los hidrocarburos, los servicios esenciales, los medios de comunicación, el sistema de salud y el educativo. Las Fuerzas Armadas deben responder a la necesidad popular de resguardar la soberanía y el territorio nacional. Las políticas socio - culturales deben ser integrales y abordadas entre estado y organizaciones populares contemplando las necesidades y aspiraciones del pueblo. Un estado nacional y popular aspira a la integración de América Latina" (Gallo, 2007:9-10). 
con recursos no materiales, pero sí de experiencia e interés en la participación política y grandes conocimientos en torno a la lucha por la supervivencia. Estos sectores poseen una importante inscripción territorial, por lo cual la solidaridad de las comunidades de los mismos, es un recurso valorable y potenciable en torno a nuevas maneras de inclusión y bienestar. También permite ir más allá de las cuestiones meramente económicas y mercantiles para considerar el aspecto cultural y las formas de expresión del pueblo argentino.

Pensar en términos de lo popular tiene que ver con una visión del espacio social como un escenario dicotómico, en el que los actores sociales desempeñan prácticas políticas que no expresan su naturaleza como sujetos sociales, sino que los constituyen como tales, de forma que la práctica política adquiere prioridad ontológica (Laclau, 2009). Lo popular encarna una lógica de articulación política, que se define en oposición con la hegemonía. En este escenario, la interacción social es negociación entre sujetos pertenecientes a colectivos de clase, cuyas identidades se constituyen en torno a intereses. Estas negociaciones son por definición desiguales. De esta manera, lo popular es una forma de pensar las identidades sociales, un modo de articular demandas dispersas; en definitiva, una manera de construir lo político. Cabe destacar que masividad no implica a lo popular, la distinción entre ambas está en el posicionamiento en el tejido social de aquellos que colectivizan sus demandas, sólo implicará un movimiento popular aquel movimiento masivo que represente a "los de abajo" (Laclau, 2009).

Para concebir un proyecto profesional que derive en un Trabajo Social nacional y popular es necesario partir de la afirmación de que nuestra práctica como profesionales implica un hecho político. Esta praxis, bajo el presente posicionamiento implica "garantizar la plena vigencia de los derechos del hombre y un marco de referencia que se apoyará en los principios de justicia social, libertad y equidad" (Dell'Aglio, 2011:65). Para llegar a tal objetivo, es necesario trazar categorías que nos sitúen en un sólido posicionamiento ideológicoacadémico-político. Una de estas categorías de las que partimos es la de ciudadano, pensando en él como aquel que posee derechos los 
cuales les fueron quitados y por los que lucha por reconquistar. "No es un necesitado. No necesita. Viene a pedir, a reclamar lo que le han quitado. Tampoco es un usuario, el usuario es el que usa algo y si no lo tiene no lo puede usar, mucho menos será un beneficiario, el beneficiario es el que se beneficia de algo, ¿qué beneficio es tener que pedir?" (Dell'Aglio, 2011:65). Esta concepción de ciudadano a la que apelamos no es una forma de invisibilizar las diferencias de clase, ya que este posicionamiento sostiene que el escenario de intervención de nuestra profesión se encuentra atravesado y a la vez fundado por la clase trabajadora, la cual fue limitada en su ciudadanía durante el largo período de implementación de políticas neoliberales en Argentina. De allí que esta forma de Trabajo Social se conciba como un espacio de resistencia para las clases populares frente a las hegemonías económicas que sojuzgan al pueblo argentino. Así como manifiesta Dell'Aglio, "de lo que se trata en última instancia es de transformar los derechos formales en derechos reales y la justicia formal en justicia social” (2011:65).

De esta forma, la profesión desde dicho posicionamiento es sostenida como un espacio de resistencia ${ }^{6}$ que lleva como estandarte y marco de referencia a la concepción de los Derechos Humanos. Esta concepción implica la defensa de los sectores vulnerados frente a los atropellos que se realizan sobre los derechos civiles, políticos y sociales, considerando la indivisibilidad de los mismos. Mediante la defensa de los Derechos Humanos es que se sostiene como estrategia de intervención dentro de la profesión a la asistencia repensándola como una recuperación de lo perdido, por parte de los sectores más vulnerados, resignificándola como una forma de reforzar las estrategias de sobrevivencia, a fin de establecer condiciones mínimas de dignidad.

\footnotetext{
6 En el presente posicionamiento el término resistencia es considerado bajo la categoría que propone Foucault, visualizando las posibilidades de transformación o sólo de lucha por la transformación social en vistas de romper con las relaciones de fuerza de clase, no sin las tensiones, contradicciones y obstáculos propios de la práctica en un escenario de contradicciones y tensiones como es el espacio social. Respecto de la categoría de resistencia Foucault dice: "Que no existen relaciones de poder sin resistencias; que éstas son más reales y más eficaces cuando se forman allí mismo donde se ejercen las relaciones de poder; la resistencia al poder no tiene que venir de fuera para ser real, pero tampoco está atrapada por ser la compatriota del poder. Existe porque está allí donde el poder está: es pues como él, múltiple e integrable en estrategias globales. La lucha de clases puede pues no ser "la ratio del ejercicio del poder' y ser no obstante 'garantía de inteligibilidad' de algunas grandes estrategias" (2008:167).
} 
Vinculado a una forma de realizar de manera concreta la redistribución social de los ingresos nacionales (Gallo, 2006:262).

Sin embargo, aunque reivindicando a la asistencia como conquista social, la misma resulta insuficiente en el ejercicio profesional como resistencia popular. Es necesario hacer eje en el fortalecimiento de la organización popular como forma de colectivización de las demandas en miras de la conquista de los derechos sociales por parte de las mayorías. A través de toda la historia nacional, las clases populares resultaron protagonistas de los acontecimientos históricos, conquistando derechos y cada vez más financiamiento público para la atención de $s u$ cuestión social. El Trabajo Social, como profesión que asiste la cuestión social, es un producto de la resistencia de los sectores populares a la dominación hegemónica, por lo que los profesionales en la misma construcción de garantías y derechos reales, debemos tejer un puente de encuentro, en el que lejos de emitir discursos sobre un "objeto de intervención”, podamos elaborar vínculos de construcción. No sin aceptar que este vínculo no se realizará en plena horizontalidad, ya que en dicha construcción dialógica las relaciones de poder se encuentran presentes.

Aún es este encuentro imposible de horizontalizar de forma completa, es posible tejer un vínculo dialógico en el que los saberes, académicos y populares, se complementen, en una intervención conjunta que permita la resistencia colectiva de sujetos que pertenecen a la misma clase. Es necesario construir una conciencia de clase en el colectivo profesional, saltando las imposiciones hegemónicas sobre la superioridad del trabajo intelectual sobre el trabajo manual. Una conciencia de clase que permita visualizarnos como parte de la clase trabajadora que necesita vender su fuerza de trabajo a cambio de medios de subsistencia, que fue abatida por las fragilizaciones en las relaciones laborales producto de las políticas de flexibilización laboral, y que se encuentra bajo los dominios del mercado económico y político para garantizarse la "dignidad" 7 .

7 Concepto vago y arbitrario resulta el de dignidad, que contiene una gran significación para la clase trabajadora que le carga el sentido de aquellos que no la intelectualizan, sino que la utilizan como estandarte de sus luchas libertarias. 
En este tipo de ejercicio de ejercicio de un Trabajo Social "popular", los ejes civilización y barbarie son superados en un acto de conciencia de clase en el que la búsqueda de protagonismo popular transforma a los profesionales que adhieren a este posicionamiento, en los canales de resistencia de la clase trabajadora en los espacios de negociación de los intereses en pugna. Los espacios estatales, principales espacios de trabajo de los trabajadores sociales, se presentan como escenarios de negociación de las clases en lucha, negociaciones que no son horizontales a causa de la cantidad de poder, es decir de capital político que poseen los sectores. Aun así, la resistencia de la "barbarie" permitió grandes reivindicaciones que se tradujeron en bienestar social para las grandes mayorías. Estas formas de resistencia no implican los errores acaecidos en la reconceptualización, sino que se plantea como un instrumento popular, conformado por parte de la considerada "barbarie" dentro de los espacios de pugna por el poder.

Un Trabajo Social dentro de la tradición nacional y popular plantea un tipo de crítica en vistas de una actividad constructiva, una crítica para avanzar. Respecto de esto, Norberto Alayón plantea que "un Trabajo Social crítico debe ser nacional y popular. Y un Trabajo Social nacional y popular debe ser crítico. Un Trabajo Social crítico de dominación y dependencia aún no definitivamente erradicadas en nuestros países, pero también debería estar en condiciones de reconocer y apoyar los procesos nacionales y populares (...) Con Paulo Freire me reafirmo, en su expresión: 'para poder mañana lo que hoy es imposible, tenemos que ir haciendo lo que hoy es posible', y ello no significa claudicación ni resignación, sino agudeza política para comprender y enfrentar en concreto (más allá del consignismo abstracto) los desafíos coyunturales (pero también estratégicos) de la historia nacional y latinoamericana" (Alayón, 2012). 
Reflexiones finales: el desafío del

ejercicio de un Trabajo Social desde el

pensamiento nacional y popular

"Para interpelar nuestras prácticas hay que decir que la trayectoria histórica del Trabajo Social indica que este ha adherido siempre a los intereses de las clases dominantes, por lo tanto, no se ha desarrollado una conciencia social en el colectivo profesional que permita desarticular definitivamente estas prácticas conservadoras buscando modelos que refuercen nuestra identidad profesional" (Dell'Aglio, 2011:65).

El escenario socio-político nacional es el de una gran politicidad y manifestación popular de todos los sectores sociales, y especialmente de los sectores populares. Las polarizaciones se han agudizado desde el año 2003 en adelante, incrementando la participación partidaria, en movimientos sociales y en organizaciones de base, reactualizando el despertar popular del año 2001. Los intereses sectoriales son cada vez más visibles y la lucha de clases más evidente. Desde nuestra profesión nos encontramos con dilemas que afectan a nuestra identidad profesional colectiva frente a los procesos del pueblo.

Desde este trabajo la propuesta se enmarca dentro del pensamiento nacional y popular, desde la cual se puede concebir al Trabajo Social como un espacio de resistencia frente a las minorías hegemónicas. Esta tarea implica un acompañamiento y fortalecimiento de la organización de los sectores populares en su lucha por los derechos sociales que fueron quitados en el período neoliberal o aquellos que nunca fueron reconocidos. Frente al surgimiento de gobiernos populares, el escenario de intervención del Trabajo Social continúa siendo un espacio de resistencia frente a las minorías hegemónicas que poseen el poder en la esfera económica nacional e internacional. De esta forma, se reconoce que el poder se disemina por la sociedad, en torno a un recorte de clase, y no se encuentra únicamente depositado en el Estado. Siendo el Estado percibido como un espacio de negociación de las clases en pugna, un escenario de relaciones dispares, en 
el que se enfrentan los intereses de las mayorías y los de la minoría hegemónica.

La resistencia que realiza este tipo de Trabajo Social tiene un doble eje de tensión en el que el trabajador como instrumento hegemónico de control y disciplinamiento social, es decir con una misión civilizadora, utiliza las mismas herramientas de legitimación de su discurso "capacitado" y su cualificación de "cuadro técnico" para intervenir en favor de los sectores populares y a su vez, en favor de las reivindicaciones de la clase a la que pertenece como trabajador asalariado. De esta forma la división entre profesional civilizado y pueblo bárbaro se cuestiona desde la conciencia de los trabajadores sociales como parte de la misma clase a la cual pertenecen los sujetos de su intervención, pero no la elimina ya que la verticalidad en las relaciones profesional-población, en el marco de la coyuntura institucional en la que se lleva adelante la profesión y en vistas de la historización de nuestra profesión intrínsecamente ligada a la misión colonizadora, es de dificultoso destierro.

De esta forma es que es posible eludir dicha misión civilizadora de nuestra profesión, considerándonos canales de la voz popular, no porque seamos mediadores, sino porque nuestra pertenencia de clase nos coloca en la misma vereda, siendo parte de esa voz popular. La visión de la intervención profesional como espacio de realización de la solidaridad de clase nos coloca lejos del colonialismo social.

La concepción de un Trabajo Social enmarcado en la lógica de los Derechos Humanos nos permite visualizar a las clases populares como seres humanos integrales, con necesidades, pero también con deseos, con una lectura propia de su situación y de la situación colectiva de su espacio de participación (partido político, movimiento social, organización de la sociedad civil, barrio, etc.) y con propuestas de acción. La misma lógica de los Derechos Humanos nos sitúa en una lectura de los sujetos de intervención como ciudadanos, es decir, sujetos de derechos, pero sin que ello nos lleve a una invisibilización de las diferencias de clase. Pero también debemos considerar que una lectura mecánica de los Derechos Humanos puede hacernos caer en la misión civilizadora de la cultura occidental, que estableciendo una 
universalidad inmutable no considera los aspectos particulares regionales, nacionales y étnicos, sino que establece normas morales inmutables. Por esto es necesaria la actitud crítica frente a la lógica de los Derechos Humanos que nos lleve a la defensa del bienestar social de los sectores populares.

La historia nacional nos interpela desde su sistemática conformación de sujetos bárbaros, los cuales fueron sometidos al sojuzgamiento social, cultural, económico y político. El Trabajo Social atravesó períodos en los cuales los proyectos profesionales hegemónicos estuvieron en sintonía con tales construcciones nacionales de dispositivos de dominación, pero también tuvieron protagonismo en tal colectivo profesional, rupturas que cuestionaron esta misión colonizadora en pos de un "empoderamiento" de los sectores populares. Hoy, con los ojos revisionistas en el pasado que nos permiten analizar el presente, trazamos un futuro inmediato en el que la profesión sea un instrumento de liberación nacional en la lucha por el poder popular.

\section{Referencias bibliográficas}

ALAYÓN, N. "¿Trabajo social crítico versus trabajo social nacional y popular?”, en: Iniciativa, espacio de debate político, social y cultural, 2012. [En línea: 01/10/2012] Disponible en: www.espacioiniciativa.com.ar/?p=7812.

ALBERDI, J. "Los problemas de las soluciones a la nueva cuestión social”. Ficha de cátedra Trabajo Social V, Escuela de Trabajo Social. Rosario, UNR, 2003.

AQUIN,N. et. al. "El Trabajo Social en las actuales relaciones Estado -Sociedad", en: AQUIN, N. (Org.) Trabajo Social, Estado y Sociedad. El Trabajo Social y las prácticas societarias. Tomo I. Buenos Aires, Espacio, 2008. Pp. 61 a 81.

ARGUMEDO, A. Los silencios y las voces de América Latina. Notas sobre el pensamiento nacional y popular. Buenos Aires, Editorial del Pensamiento Popular, 1993.

BENTOS, N. "Estado y trabajadores en Argentina. Una mirada sobre la orientación ejercida por el Trabajo Social en los procesos de construcción de hegemonía (18801976)". Tesina de grado, Escuela de Trabajo Social, Rosario, UNR, 2008.

BOLESO, H. "Derechos Humanos, sociedad del trabajo e inclusión social”. Clase inaugural del curso organizado por la Primera Cátedra de Derechos Humanos de Corrientes.12.03.2008. [En línea: 03/10/2012] Disponible en: www.vistadecausa.com.ar. 
CASTEL, R. Las metamorfosis de la cuestión social. Buenos Aires, Paidós, 1997.

DE JONG, E. "Familia y trabajo social”. Ficha de Cátedra (mimeo). Seminario de Familia. Facultad de Trabajo Social, Paraná, UNER, 1998.

DELL’AGLIO, M. "Un modelo de intervención social en dos modelos de país. ¿Qué hacemos los trabajadores sociales?”, en: Revista Debate Público. Reflexión de Trabajo Social. Año 2 - Nro. 3, Carrera de Trabajo Social, Facultad de Ciencias Sociales, Buenos Aires, UBA, 2011.

DONZELOT, J. La policía de las familias. Madrid, Editorial Pre - textos, 1998.

FEINMANN, J. P. "Peronismo. Filosofía política de una obstinación argentina”, en: Página/12, Buenos Aires, Entregas especiales con el Diario Página/12, 2008.

FOUCAULT, M. Microfísica del poder. Buenos Aires, Siglo XXI editores, 2008.

FRANCO, D. Concepto, historia y métodos de la Asistencia Social. Buenos Aires, Baiocco, 1947.

GALLO, M. Qué somos. Historia, política y Trabajo Social en la Argentina. Rosario, UNR Editora, 2005.

GALLO, M. "Informe de situación. Segundo avance de una propuesta laboral de Trabajo Social Estatal - Comunitario”. Inédito. Rosario, 2007.

IAMAMOTO, M. El Servicio Social en la contemporaneidad. Trabajo y formación profesional. Sao Paulo, Cortez, 2003.

KLIKSBERG, B. Pobreza, el drama cotidiano. Clave para una nueva gerencia social eficiente. Caracas, Tesis Grupo Editorial Norma Clad- PNUD, 1995.

NETTO, J. P. “Trabajador social domesticado o crítico”. Conferencia. Mimeo. Buenos Aires, 1995.

OLIVA, A. "Intervención y espacio ocupacional en los orígenes del trabajo social”, en: Revista Plaza Pública, Año 1, № 1. Tandil, Diciembre 2008.

OLIVA, A. "Antecedentes del trabajo social en Argentina: asistencia y educación sanitaria”, en: Revista del Departamento de Trabajo Social, Facultad de Ciencias Humanas, Universidad Nacional de Colombia, N 8. Bogotá, 2006. Pp. 73-86.

PARRA, G. Antimodernidad y Trabajo Social. Orígenes y expansión del Trabajo Social Argentino. Buenos Aires, Espacio, 2001.

PELLEGRÍ VIAÑA, X. "El poder en el trabajo social: Una aproximación desde Foucault”, en: Cuadernos de Trabajo Social. Vol. 17. Madrid, Ediciones Complutense, 2004. Pp. 21-43.

SENETT, R. El respeto. Madrid, Editorial Anagrama, 2005. 